\title{
The Relationship between Hearing Impairment and Cognitive Function in Middle-Aged and Older Adults: A Meta-Analysis
}

\author{
Soo Jung Lee \\ Department of Audiology and Speech-Language Pathology, Daegu Catholic University, Gyeongsan, Korea
}

Correspondence: Soo Jung Lee, PhD Department of Audiology and Speech-Language Pathology, Daegu Catholic University, 13-13 Hayang-ro, Hayang-eup, Gyeongsan 38430, Korea Tel: $+82-53-850-2540$

Fax: $+82-53-359-6780$

E-mail: sj207@hanmail.net

Received: March 6, 2018

Revised: June 10, 2018

Accepted: June 10, 2018

\begin{abstract}
Objectives: Although many studies have attempted to demonstrate the effect of hearing impairment on cognitive function, findings across studies have been relatively inconsistent. The current study aimed to synthesize the findings of previous cross-sectional studies which compared cognitive performance between middle-aged and older adults with hearing impairment and normal hearing controls. Methods: A systematic literature review was performed using meta-analysis (Comprehensive Meta-Analysis version 3.0). A total of 11 studies meeting the inclusion criteria were included in the current meta-analysis. The effect sizes were obtained by Hedges' $g$ with a $95 \%$ confidence interval using a random effect model. Results: Middle-aged and older adults with hearing impairment showed lower cognitive performance as compared to normal hearing controls, especially in the domains of executive function/processing speed, working memory, language, verbal memory, and general cognition. There was no significant difference in visuospatial ability between groups. Also, regardless of whether cognitive measures primarily rely on auditory function or not, hearing-impaired adults showed lower performance than normal hearing controls. Conclusion: The current meta-analytic findings indicate that hearing impairment is associated with cognitive deficits in middle-aged and older adults.
\end{abstract}

Keywords: Hearing impairment, Cognitive function, Middle-aged and older adults, Metaanalysis
노인성 난청(age-related hearing impairment, 또는 presbycusis) 은 신체 노화과정의 일부로 발생하는 감각신경성 질환의 하나로서 (Gates \& Mills, 2005), 노인 인구에서 나타나는 질환들 가운데 관 절염, 고혈압 다음으로 가장 흔한 만성 질환으로 보고된 바 있다 (Lethbridge-Cejku, Schiller, \& Bernadel, 2004). 노인성 난청의 유 병률은 65-74세 연령층에서 약 $25 \%-30 \%, 75$ 세 이상의 연령층에서 는 약 $50 \%$ 에 이르며(Agrawal, Platz, \& Niparko, 2008), 노인성 난청 이 나타나기 시작하는 연령대는 점점 더 빨라져 50대부터 청력 저 하가 나타나기 시작한다(Homans et al., 2017). 일반적으로 초기에는 양측 대칭성의 고주파수대 청력 손실을 보이고, 진행할수록 어음 주파수 영역에서도 청력 손실이 나타나는 것이 특징적이다(Gates \& Mills, 2005). 아직까지 국내외에서 노인성 난청을 진단하기 위한
통일된 기준이 정해지지 않은 상태이나, 일반적으로는 순음청력검 사(pure-tone audiometry)상 평균 청력 역치가 $25 \mathrm{~dB} \mathrm{HL}$ 이상의 감각신경성 난청을 보이면서 양측 귀의 청력이 대칭성을 나타날 때 노인성 난청을 진단할 수 있다(Katsarkas, \& Ayukawa, 1986). 노인 성 난청은 노년층의 일상생활 의사소통을 어렵게 함으로써 대인관 계 기피나 사회적 고립을 야기하고, 나아가 우울증이나 심리적 소 외감 등 정신적 문제를 유발하여 노년기 삶의 질을 저하시키는 요 인이 된다(Ciorba, Bianchini, Pelucchi, \& Pastore, 2012).

이러한 감각 기능의 저하와 더불어 노화로 인한 전반적인 인지능 력의 감퇴는 잘 알려져 있다. 기억력은 노화로 인해 감퇴하는 주요한 인지영역으로서, 특히 언어적 기억력의 저하가 두드러진다(Rönnlund, Nyberg, Bäckman, \& Nilsson, 2005; Salthouse, 2009). 또한, 
일시적으로 정보를 저장하고 처리하기 위해 요구되는 작업기억도 노화와 더불어 감퇴한다(Bopp \& Verhaeghen, 2005; Connor, 2001). 집행기능 역시 저하되는데, 집행기능이란 일련의 활동들을 조직화 하여 수행하는 능력을 일컫는다(Buckner, 2004). 즉, 목표자극 외 에 간섭자극의 방해가 있을 때, 간섭자극의 효과를 배제하면서 목 표자극에만 주의를 기울이는 선택적 주의나 여러 가지 과제의 수 행에 주의를 분산시켜 유지할 수 있는 분할 주의, 필요에 따라 여러 인지능력을 다양하게 활용할 수 있는 인지적 유연성 등이 모두 집 행기능의 핵심 개념에 해당한다(McCabe, Roediger, McDaniel, Balota, \& Hambrick, 2010). 정보처리속도 역시 노화와 함께 저하 되어 노인들은 특정 과제를 수행할 때 더 많은 시간이 소요된다 (Salthouse, 1996).

최근 들어 노화 관련 감각 기능의 변화가 인지기능에 미치는 영 향에 주목하기 시작하면서, 노인성 난청과 노년층의 인지기능 저하 간 관련성을 밝히고자 하는 다수의 종단연구가 시행되었다. $\operatorname{Lin}$ 등 (2011)은 약 11.9년 동안 639명의 성인을 추적한 결과, 기초선 단계 에서 난청으로 진단된 성인이 정상 청력의 성인보다 치매 발생율이 높았으며, 난청 중증도가 높아짐에 따라 치매에 대한 위험비(hazard ratio) 역시 증가함을 확인하였다. Lin 등(2013)의 연구에서도 난청 환자에서 인지기능 감퇴가 가속화되었는데, 정상 청력의 성인 에 비해 난청 환자군에서 인지기능 선별검사인 수정된 간이정신상 태검사(modified mini-mental state test)와 집행기능 및 정보처리 속도를 측정하는 기호숫자치환검사(digit symbol substitution test) 의 점수가 매년 각각 약 0.2 점, 0.19 점씩 더 큰 폭으로 저하되었다. 이 러한 종단연구 결과들은 노인성 난청이 인지기능 감퇴를 가속화하 고 치매 등의 인지장애를 유발하는 위험인자임을 시사한다고 하겠 으나(Albers et al., 2015; Panza, Solfrizzi, \& Logroscino, 2015), 모든 연구들이 일관적으로 노인성 난청과 인지기능 간의 유의한 상관성 을 확인한 것은 아니다. Lin 등(2004)은 약 4.4년에 걸친 전향적 연 구를 통해 난청이 노년층의 전반적인 인지능력에 미치는 영향이 없 는 것으로 결론 내렸으며, Anstey, Luszcz와 Sanchez (2001)도 마찬 가지로 난청이 구어능력, 기억력, 정보처리속도 등의 어떠한 인지영 역에도 영향을 미치지 않는다고 보고하였다.

종단연구뿐만 아니라 다수의 횡단연구들을 통해서도 노인성 난 청과 인지능력 간의 관련성을 파악하고자 하는 노력이 이루어져왔 다. 즉, 난청이 있는 노년층 집단과 정상 청력의 노년층 집단 간 인지 능력을 비교하였는데, 앞서 살펴본 종단연구와 마찬가지로 연구 간 결과가 일관적이지 않았다. 일부 연구들은 난청이 있는 노년층이 정상 노년층에 비해 인지능력이 저하됨을 보고하였으나(Desjardins \& Doherty, 2013; Guerreiro \& Van Gerven, 2017; Sugawara et al., 2011; Tay et al., 2006), 또 다른 연구들에서는 두 집단 간 인지능 력에 차이가 나타나지 않은 경우도 있었다(Deal et al., 2015; Jayakody, Friedland, Eielboom, Martins, \& Sohrabi, 2018). 이러한 연 구 간 불일치는 각각의 개별 연구들이 평가한 인지영역 및 시행한 인지검사가 일관적이지 않고 이질성이 크다는 측면에서 비롯할 수 있다(Taljaard, Olaithe, Brennan-Jones, Eikelboom, \& Bucks, 2016; Wayne \& Johnsrude, 2015). 예컨대, 작업기억을 평가하기 위해 읽 기 폭 검사(reading span test)를 시행한 연구에서는 난청이 있는 노 년층이 정상 노년층에 비해 저하된 수행력을 보였으나(Desjardins \& Doherty, 2013), 숫자 거꾸로 따라하기(backward digit span test) 를 시행한 연구에서는 두 집단 간 수행력 차이가 나타나지 않았다 (Deal et al., 2015). 또한, 적은 수이긴 하나 일부 연구들에서는 종합 적인 신경심리검사를 시행한 결과를 통하여 두 집단 간 인지능력의 차이를 설명하고자 한 반면(Deal et al., 2015; Jayakody et al., 2018), 대다수의 연구들에서는 한두 가지의 인지검사들을 선택적으로 시 행하여 집단 간 차이를 살펴보는 데 그쳤다. 더불어, 각각의 연구들 이 인지과제를 선택함에 있어 청각 기능에 대한 의존도를 고려하였 는가 하는 점에서도 차이가 있다. 즉, 난청이 인지저하에 미치는 영 향을 파악하기 위해서는 난청으로 인해 단순히 검사 자극을 정확 히 듣지 못해서 발생할 수 있는 평가 오류의 가능성을 최소화해야 한다. 일부 연구자들은 잘 훈련된 임상가에 의해 인지검사가 시행될 경우 이러한 가능성은 매우 낮다고 주장하였으나(Lin et al., 2011b; Lindenberger, Scherer, \& Baltes, 2001), 청각 기능에 대한 의존도가 높은 인지과제(예: 청각적 언어학습 검사[auditory verbal learning test]) 위주로만 평가하는 경우에는 이러한 가능성을 완전히 배제하 기란 어렵다.

이처럼 난청 환자군과 정상군 간 인지능력을 비교한 개별 연구결 과들을 종합적으로 해석하는 것은 쉽지 않다. 이러한 노력의 일환 으로, Taljaard 등(2016)은 메타분석을 통하여 처음으로 난청과 인 지기능 간의 관련성을 체계적으로 파악하고자 시도하였다. 연구 결 과, 난청 환자군의 경우 정상군에 비해 단기기억/작업기억, 장기기 억, 집행능력, 의미지식, 주의집중 및 정보처리속도가 모두 저하되 는 것으로 나타났다. 단, Taljaard 등(2016)의 연구는 전 연령층의 난 청 성인을 대상으로 하였기 때문에 장노년층에서 난청이 인지기능 에 미치는 영향을 알 수 없다. 앞서 살펴본 바와 같이, 청년층과 달 리 장노년층의 경우 노화에 따른 감각 및 인지기능 저하가 명백하 게 나타나므로, 난청이 인지기능에 미치는 영향은 청년층과 장노년 층에서 서로 다르게 작용할 가능성이 있다. 이에, 본 연구에서는 장 노년층을 대상으로 한 메타분석을 통하여 난청이 인지기능에 미치 는 영향을 체계적이며 종합적으로 분석하고자 하였다. 


\section{연구방법}

\section{자료수집}

문헌검색

2018년 2월에 국외(PubMed, ProQuest, EBSCOhost) 3개, 국내 (RISS, DBPIA) 2개의 데이터베이스에서 문헌 검색을 실시하였다. 난청, 인지, 노인 관련 검색어를 'AND'로 설정하여 검색하되(예: hearing impairment AND cognitive function AND older adults), 2000년 이후 국내외 학술지에 게재된 연구만으로 제한하여 세부 검색을 실시하였으며, 국외 데이터베이스의 경우 영어 논문만을 대 상으로 하였다. 문헌 수집에 사용된 검색어로는 'hearing impairment', 'hearing loss', 'age-related hearing impairment', 'age-related hearing loss', 'presbycusis', 'cognition', 'cognitive function', 'older adults', 'elderly', '난청', ‘인지', ‘노인', ‘노년층’이었다. 국내 데이터 베이스에서 주제어 '인지'로 검색하였을 때, 말소리 지각(speech perception) 연구의 핵심어로 주로 사용되는 인지(recognition)로 검색된 결과들은 모두 제외하였다.

\section{논문 선정기준}

문헌검색 결과, PubMed에서 633편, ProQuest에서 785편, EBSCOhost에서 82편이 검색되었으며, RISS 및 DBPIA에서는 각각 0 편이 검색되어 총 1,500 편의 연구가 검색되었다. 논문의 선정기준 및 제외기준에 따라 1,489 편이 제외되어 총 11 편의 논문이 선정되었 다. 총 11 편의 논문 가운데 7 편을 제외한 나머지 4 편의 논문은 다음 과 같은 이유로 각각의 논문이 2 개의 자료로 나누어 분석되었다. 4 편 가운데 3편의 논문(Deal et al., 2015; Jayakody et al., 2018; Suga- wara et al., 2011)은 난청 정도에 따라 연구대상을 구분(예: 정상 청 력 vs. 경도 난청; 정상 청력 vs. 중고도 난청)하여 각각 비교·분석하 였으므로 본 메타분석에서도 2 개의 자료로 나누어 따로 분석하였 고, 나머지 1편의 논문(Guerreiro \& Van Gerven, 2017) 역시 대상군 을 달리하여 각각 다른 인지검사를 실시하였으므로 마찬가지로 2 개의 자료로 나누어 분석하였다. 즉, 본 메타분석의 연구대상으로 최종 15 개의 자료를 선정하였다. 논문 선정기준 및 선정과정은 Figure 1 과 같으며, 선정된 개별 논문들의 특성을 Table 1에 요약하여 제시하였다.

개별 인지검사들을 6 개의 인지영역(전반적 인지기능, 집행기능 및 정보처리속도, 작업기억, 언어, 언어적 기억, 시공간 능력)에 따라 분류하였을 때, 선별검사를 통한 전반적 인지기능을 평가한 연구 는 5편, 집행기능/정보처리속도를 평가한 연구는 9편, 작업기억을 평가한 연구는 10 편, 언어능력을 평가한 연구는 8 편, 언어적 기억을 평가한 연구는 13 편, 시공간 능력을 평가한 연구는 5편으로 나타났 다. 각각의 개별 연구에서 2 개 이상의 인지검사 결과를 보고한 경우 는 중복하여 측정하였다(Table 2).

다음으로, 과제 수행 시에 청각 기능을 주요하게 필요로 하는가 에 따라 인지검사를 두 부류로 분류하였을 때, 청각 기능이 주요하 게 요구되는 인지검사를 포함한 연구는 13 편, 청각 기능이 주요하 게 요구되지 않는 인지검사를 포함한 연구는 37편이었다. 마찬가지 로 각각의 개별 연구에서 2 개 이상의 인지검사 결과를 보고한 경우 는 중복하여 측정하였다(Table 2). 청각 기능에 대한 의존도를 판단 하는 기준으로는 $\operatorname{Lin}$ 등(2013)의 연구에서와 같이 검사 자극이 청 각적으로 제시되는 경우는 청각 기능이 주요하게 요구되는 검사로 분류하였고, 검사자의 지시사항을 이해하는 것을 제외하고는 과제

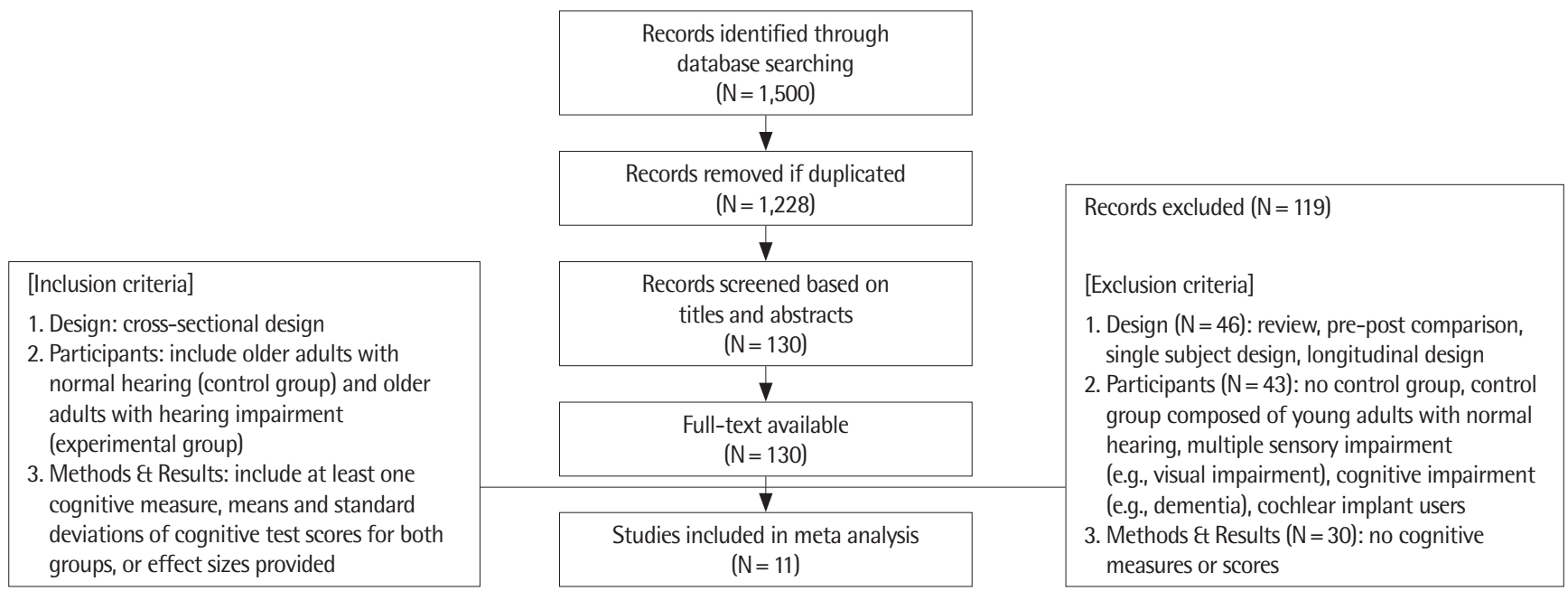

Figure 1. Flowchart of studies included from database search. 


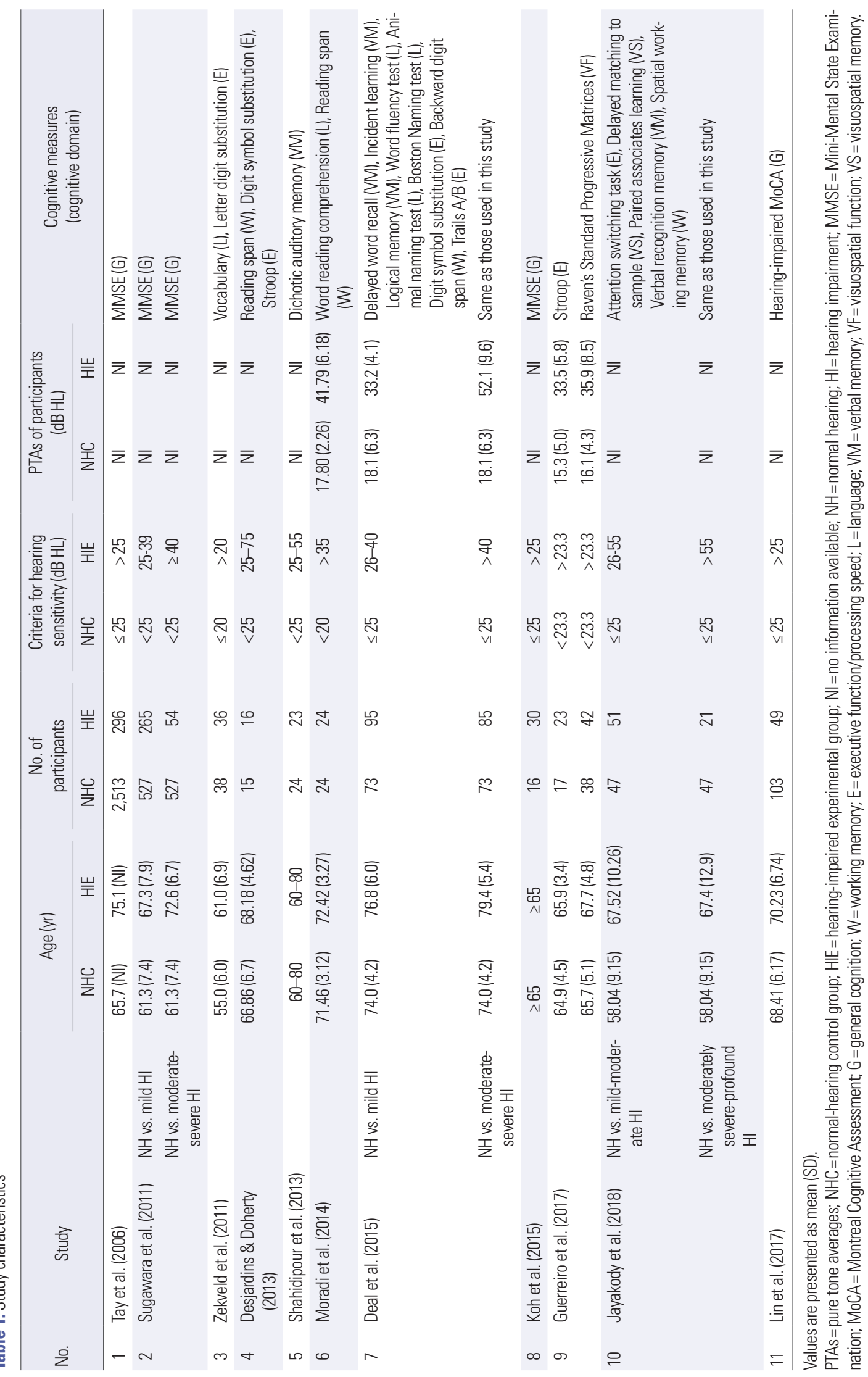


Table 2. Categorizations of cognitive measures into six cognitive domains or two types of measuring

\begin{tabular}{|c|c|c|}
\hline & Measure & $\begin{array}{l}\text { No. of } \\
\text { articles }\end{array}$ \\
\hline \multicolumn{3}{|l|}{ Cognitive domains } \\
\hline \multirow[t]{2}{*}{ General cognition } & MMSE & \\
\hline & Hearing-impaired MoCA & 5 \\
\hline \multirow{5}{*}{$\begin{array}{l}\text { Executive function/ } \\
\text { processing speed }\end{array}$} & Digit symbol substitution test & \\
\hline & Letter digit substitution test & \\
\hline & Stroop test & \\
\hline & Trail making test $\mathrm{A} / \mathrm{B}$ & \\
\hline & Attention switching task & 9 \\
\hline \multirow[t]{3}{*}{ Working memory } & Backward digit span test & \\
\hline & Reading span test & \\
\hline & Spatial working memory test & 10 \\
\hline \multirow[t]{5}{*}{ Language } & Word vocabulary test & \\
\hline & Word reading comprehension test & \\
\hline & Word fluency test & \\
\hline & Animal naming test & \\
\hline & Boston Naming test & 8 \\
\hline \multirow[t]{5}{*}{ Verbal memory } & Dichotic auditory memory & \\
\hline & Delayed word recall & \\
\hline & Incident learning & \\
\hline & Logical memory & \\
\hline & Verbal recognition memory & 13 \\
\hline \multicolumn{3}{|l|}{ Visuospatial ability } \\
\hline \multirow[t]{2}{*}{ Visuospatial memory } & Delayed matching to sample & 4 \\
\hline & Paired associates learning & \\
\hline Visuospatial function & Raven's Standard Progressive Matrices & 1 \\
\hline \multicolumn{3}{|c|}{ Types of measuring } \\
\hline \multirow{6}{*}{$\begin{array}{l}\text { Measures relying on } \\
\text { auditory function }\end{array}$} & MMSE & 13 \\
\hline & Backward digit span test & \\
\hline & Dichotic auditory memory test & \\
\hline & Delayed word recall & \\
\hline & Incident learning & \\
\hline & Logical memory & \\
\hline \multirow{17}{*}{$\begin{array}{l}\text { Measures not relying } \\
\text { on auditory function }\end{array}$} & Hearing-impaired MoCA & 37 \\
\hline & Stroop test & \\
\hline & Trail making test $A / B$ & \\
\hline & Raven's Standard Progressive Matrices & \\
\hline & Reading span test & \\
\hline & Word fluency test & \\
\hline & Animal naming test & \\
\hline & Boston Naming test & \\
\hline & Digit symbol substitution test & \\
\hline & Letter digit substitution test & \\
\hline & Word reading comprehension test & \\
\hline & Attention switching task & \\
\hline & Delayed matching to sample & \\
\hline & Paired associates learning & \\
\hline & $\begin{array}{l}\text { Verbal recognition memory (non-auditory } \\
\text { version) }\end{array}$ & \\
\hline & Word vocabulary test & \\
\hline & Spatial working memory test & \\
\hline
\end{tabular}

MMSE = Mini-Mental State Examination; MoCA=Montreal Cognitive Assessment.
수행 시 듣기능력이 주요하게 요구되지 않는 검사는 청각 기능에 대한 의존도가 낮은 검사로 분류하였다. 예컨대, 숫자 거꾸로 따라 말하기 과제나 언어학습검사의 단어 회상 과제의 경우, 숫자나 단 어와 같은 검사자극들이 피험자에게 청각적으로 제시되므로 청각 기능이 주요하게 요구되는 검사로 분류하였다. 반면, 대면 이름대 기 검사나 단어 유창성 검사, 기호숫자치환검사 등은 검사 자극이 청각적으로 제시되지 않아 실제 과제를 수행할 때 피험자가 청각 기능을 사용하는 정도가 낮으므로 청각 기능에 대한 의존도가 낮 은 검사로 분류하였다. 단, Jayakody 등(2018)의 연구에 포함된 구 어재인기억(verbal recognition memory) 과제의 경우, 일반적으로 는 검사 자극이 청각적으로 제시되나 해당 연구에서는 컴퓨터 화 면을 통해 12 개의 단어를 제시한 후 피험자가 이를 기억하여 회상 하거나 재인하게 하는 방법을 사용하였으므로 청각 기능에 대한 의존도가 낮은 검사로 분류하였다.

\section{자료분석}

\section{연구의 질적 평가}

메타분석에 포함한 횡단적 연구들의 질적 평가를 위해 Hwang과 Kim (2014)이 Gersten 등(2005)의 필수 질적 지표(essential quality indicator)를 차용 및 수정한 방법을 사용하였다. 질적 평가 영역은 연구 대상자, 평가 절차, 결과 측정, 자료분석의 네 가지 영역으로, 각 영역에 해당하는 질적 지표들에 대하여 적합 혹은 부적합으로 개별 연구들을 평가하였다. 연구 대상자에 대한 질적 지표들로는, 첫째, 대상자가 장애나 결함을 보이는지를 확인하기 위한 충분한 정보가 제시되었는가, 둘째, 대상자의 관련 특성들이 연구 상황에 걸쳐 유사하도록 적절한 절차가 사용되었는가, 셋째, 검사자에 대 한 충분한 정보가 제시되었는가이다. 평가 절차에 대한 지표로는 연구 절차 및 채점 체계가 명시되었는가, 결과 측정에 대한 지표로 는 기술적 통계치가 제시되었는가, 자료분석에 대한 지표로는 자료 분석방법이 연구의 주요 목표 및 가설에 적합한가이다. Hwang과 $\mathrm{Kim}$ (2014)이 제시한 평가 방법에 따라 질적 평가를 시행한 결과, 본 연구에 수집된 논문들은 모두 분석에 적합한 것으로 평가되었다.

\section{자료의 코딩}

메타분석에 포함된 연구들은 일차적으로 연구자, 출판연도, 연 구대상 수, 연구대상 연령, 청력, 시행한 인지검사들에 따라 코딩 하 였으며, 종속측정치에 해당하는 인지검사 결과는 논문에서 제시된 통계값으로 분류하여 코딩하였다. 개별 인지검사들에 대해서는, 첫 째, 각각의 인지검사들이 평가하는 인지영역(전반적 인지기능, 집행 기능 및 정보처리속도, 작업기억, 언어, 언어적 기억, 시공간 능력)에 
따라 분류하거나, 둘째, 각각의 인지검사가 청각 기능을 주요하게 요 구하는가, 요구하지 않는가에 따라 두 유형으로 분류하였다(Table 2).

\section{신뢰도 평가}

언어병리학 박사과정 대학원생 1 인이 전체 연구를 다시 코딩 후 효과크기를 산출하여 각 항목별로 일치한 수의 비율을 측정한 결 과 평가자 간 신뢰도는 $100 \%$ 를 나타내었다.

\section{출판 편향}

메타분석에 포함된 연구들로부터 나타난 분석결과가 해당 주제에 대해 수행된 모든 연구들의 결과를 대표하지 못할 때 출판 편향(publication bias)이 발생한다. 메타분석에서는 표본 크기가 작은 연구들 이 상대적으로 큰 효과크기를 보이는 경향이 있는데, 이러한 경우 출 판 편향 오류가 발생할 수 있다. 이러한 오류의 유무를 확인하기 위하 여 표본의 크기와 효과크기의 관계를 나타내는 Funnel plot을 이용 할 수 있다. Funnel plot은 수평축에는 효과크기를, 수직축에는 표준 오차를 나타내는데, 효과크기 측면에서 메타분석에 포함된 데이터 들의 오류가 없다면 좌우 대칭의 형태가 나타나지만, 비대칭의 모습을 보인다면 이것은 데이터에 오류가 있음을 나타낸다(Hwang, 2014). 비대칭을 파악하는 것은 시각적으로 확인하는 방법 및 통계적으로 검증하는 방법 두 가지가 있는데, 통계적 분석으로 가장 많이 활용되 는 방법인 Egger의 회귀분석(Egger's regression test) (Egger, Smith, Schneider, \& Minder, 1997)을 시행한 결과 본 메타분석 결과에는 출 판 편향 오류가 없음을 확인하였다 $(p=.363)$ (Figure 2).

\section{메타분석}

본 메타분석 연구의 구체적인 목적은 다음과 같다. 첫째, 장노년

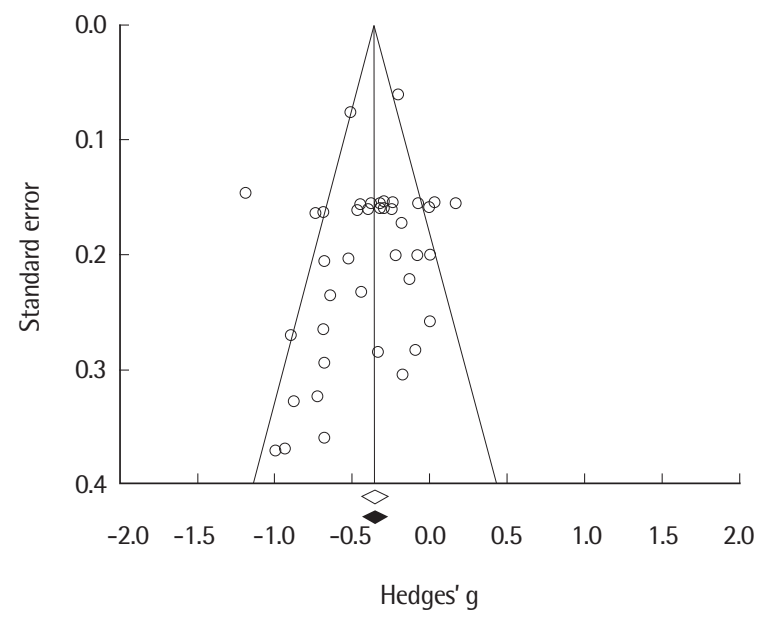

Figure 2. Funnel plot of standard error by Hedges' g.
층에서 청력 손실군과 정상 청력의 대조군 간 종합적 인지능력 차 이에 대한 효과크기를 산출한다. 둘째, 인지영역별로 청력 손실군 과 정상 청력의 대조군 간 인지능력 차이에 대한 효과크기를 각각 산출한다. 셋째, 청각 기능에 의존하는 정도에 따른 인지과제별로 청력 손실군과 정상 청력의 대조군 간 인지능력 차이에 대한 효과 크기를 각각 산출한다.

이에, 메타분석을 위한 통계프로그램인 Comprehensive MetaAnalysis version 3.0을 이용하여 효과크기를 산출하였다. 효과크 기는 Hedges' $\mathrm{g}$ 를 사용하였으며, 평균효과크기는 연구 간 표본크 기의 차이를 고려한 가중효과크기(weight effect size)를 사용하였 다. $95 \%$ 신뢰구간을 기준으로 효과크기의 유의성을 평가하였으며, 각 개별 연구들 간 효과크기의 이질성을 가정하는 무선효과모형 (random effect model)을 사용하였다. 일차적으로 전체 11편의 연 구를 대상으로 평균효과크기를 계산하였으며, 이차적으로 6 개의 인지영역에 따른 효과크기 및 청각 기능에 의존하는 정도에 따라 분류한 인지과제별로 효과크기를 각각 계산하였다.

\section{연구 대상}

청력 손실군의 연령은 평균 61.0-79.4세로 총 대상자 수는 1,110 명이었으며, 정상 청력의 대조군의 연령은 평균 55.0-74.0세로 총 대 상자 수는 4,082 명이었다. 최종 분석된 15 편의 자료 중 12 편이 임상 에서 일반적으로 사용하는 정상 청력의 기준인 $0.5,1,2,4 \mathrm{kHz}$ 역 치를 이용한 4 분법 평균 청력(4 pure tone averages; 4 PTAs) $25 \mathrm{~dB}$ $\mathrm{HL}$ 미만을 적용하였고, 나머지 3편 중 2편은 $20 \mathrm{~dB} \mathrm{HL}$ 미만, 한 편 은 $23.3 \mathrm{~dB} \mathrm{HL}$ 미만을 적용하였다. 청력 손실군의 청력은 연구마다 다소 차이가 있었는데, $20 \mathrm{~dB} \mathrm{HL}$ 이상 1편, $23.3 \mathrm{~dB} \mathrm{HL}$ 이상 2 편, 25 $\mathrm{dB} \mathrm{HL}$ 이상 3 편, 경도 난청 $(25-40 \mathrm{~dB} \mathrm{HL})$ 만 대상으로 한 연구 2편, 경중도 난청 $(25-55 \mathrm{~dB} \mathrm{HL})$ 을 대상으로 한 연구 2편, 경도-중고도 난청(25-75 dB HL)을 대상으로 한 연구 1편, 중도 이상 난청(>35 $\mathrm{dB} \mathrm{HL}$ 또는 $>40 \mathrm{~dB} \mathrm{HL})$ 을 포함한 연구 3편, 중고도 이상 난청 (>55 dB HL)을 포함한 연구 1편이 포함되었다. 총 15 편의 자료 가 운데 5 편이 청력 손실군과 대조군의 평균 청력을 구체적으로 제시 하였으며, 청력 손실군의 평균 청력은 33.2-52.1 dB HL, 대조군의 평균 청력은 15.3-18.1 dB HL로 나타났다(Table 1).

\section{연구결과}

\section{집단 간 종합적 인지능력 비교}

청력 손실군과 정상 청력의 대조군 간 종합적 인지능력 차이는 효과크기 -.352 (95\% CI, -.440 to -.265; p<.001)로서, 청력 손실군 


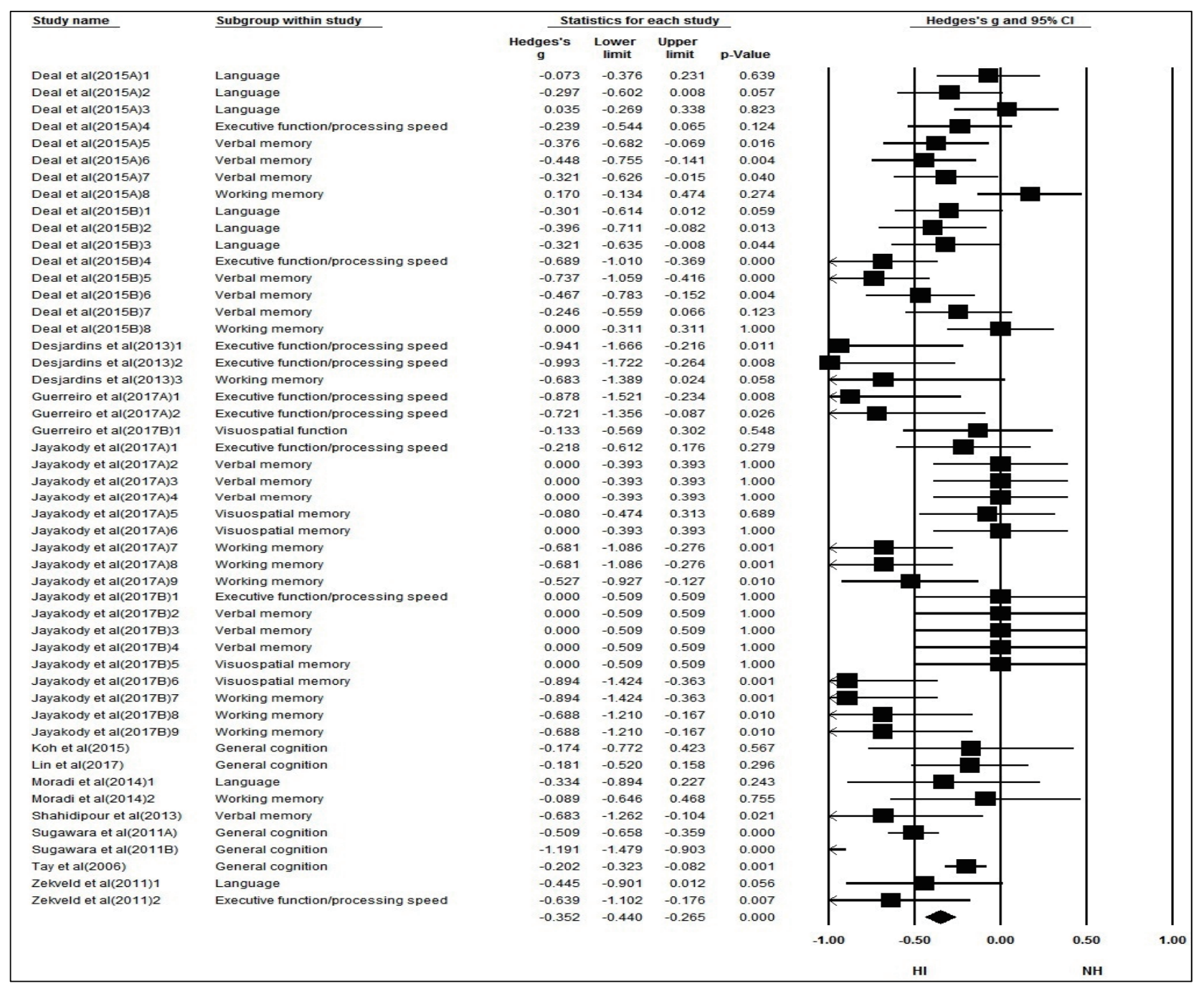

Figure 3. Forest plot for overall cognitive function.

$\mathrm{HI}=$ hearing-impaired experimental group; $\mathrm{NH}=$ normal-hearing control group.

Table 3. Summary of effect sizes for cognitive function

\begin{tabular}{|c|c|c|c|c|}
\hline \multirow{2}{*}{ Variable } & \multirow{2}{*}{$\begin{array}{c}\text { Effect size } \\
\text { (Hedges' g) }\end{array}$} & \multicolumn{2}{|c|}{ 95\% Confidence interval } & \multirow{2}{*}{$p$-value } \\
\hline & & Lower & Upper & \\
\hline Overall & -.352 & -.440 & -.265 & $<.001$ \\
\hline \multicolumn{5}{|l|}{ Cognitive domains } \\
\hline General cognition & -.468 & -.800 & -.135 & .006 \\
\hline Executive function/processing speed & -.521 & -.741 & -.301 & $<.001$ \\
\hline Working memory & -.447 & -.704 & -.189 & .001 \\
\hline Language & -.242 & -.361 & -.123 & $<.001$ \\
\hline Verbal memory & -.276 & -.417 & -.135 & $<.001$ \\
\hline Visuospatial ability & -.196 & -.488 & .096 & .188 \\
\hline \multicolumn{5}{|l|}{ Types of measuring } \\
\hline Cognitive measures relying on auditory function & -.397 & -.575 & -.218 & $<.001$ \\
\hline Cognitive measures not relying on auditory function & -.328 & -.425 & -.231 & $<.001$ \\
\hline
\end{tabular}




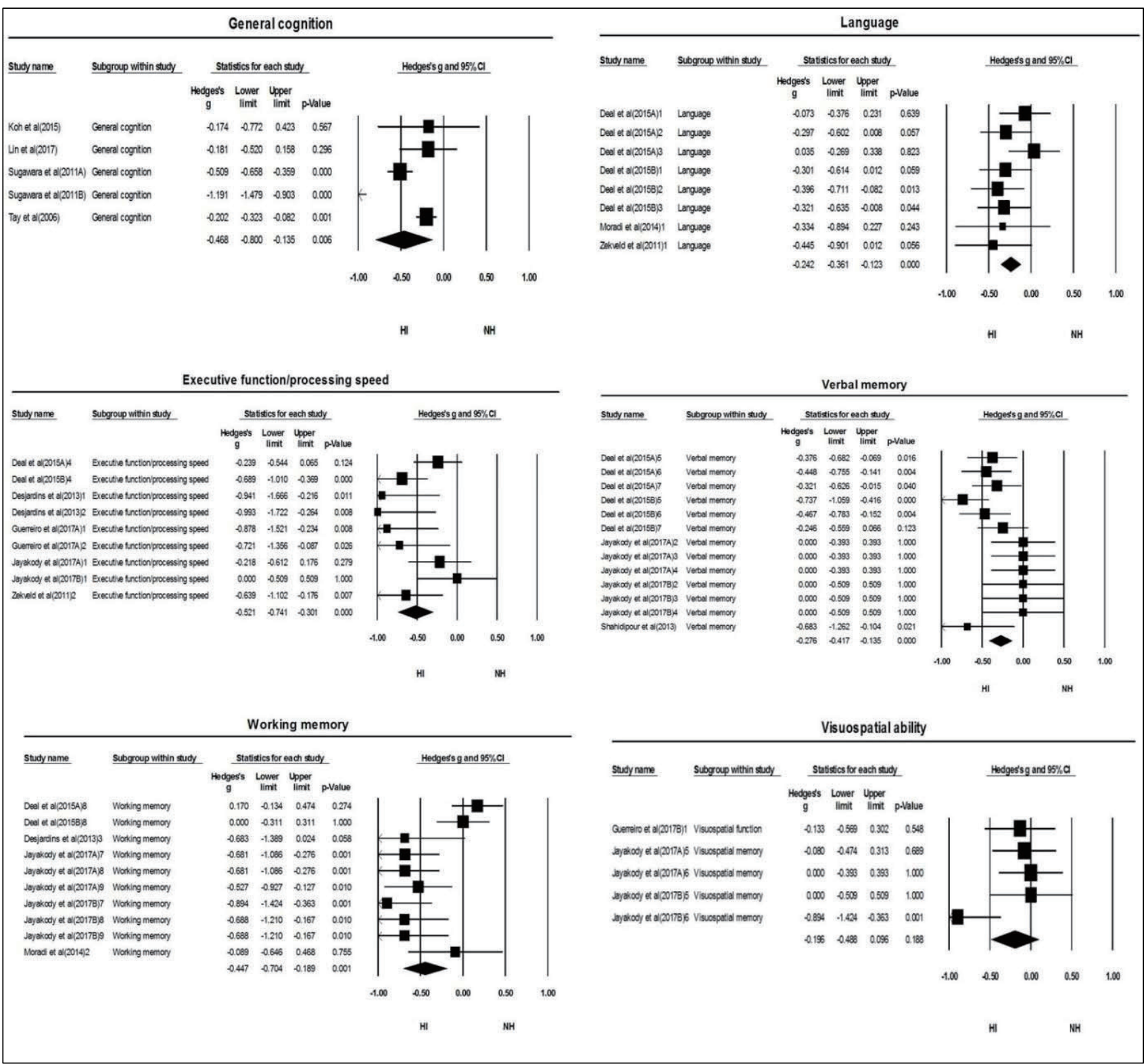

Figure 4. Forest plot for each cognitive domain.

$\mathrm{HI}=$ hearing-impaired experimental group; $\mathrm{NH}=$ normal-hearing control group.

이 대조군에 비해 전체적으로 낮은 인지능력을 보였다(Figure 3, Table 3).

\section{인지영역별 집단 간 수행력 비교}

6 개의 인지영역별로 두 집단 간 수행력의 차이를 살펴보면 다음 과 같다(Figure 4, Table 3). 첫째, 선별검사에서 나타난 전반적 인지 기능의 측면에서 효과크기 -.468 (95\% CI, -.800 to -.135; $p=.006)$, 둘째, 집행기능/정보청리속도 측면에서 효과크기 -.521 (95\% CI, -.741 to -.301; $p<.001)$, 셋째, 작업기억 측면에서 효과크기 -.447
(95\% CI, -.704 to -.189; $p=.001$ ), 넷째, 언어능력 측면에서 효과크기 -.242 (95\% CI, -.361 to -.123; $p<.001)$, 다섯째, 언어적 기억력 측면 에서 효과크기 -.276 (95\% CI, -.417 to -.135; $p<.001)$ 로, 청력 손실 군이 정상 청력의 대조군에 비해 전반적 인지기능, 집행기능/정보 처리속도, 작업기억, 언어능력, 언어적 기억력이 모두 낮게 나타났 다. 반면, 여섯째, 시공간능력 측면에서는 효과크기 -.196 (95\% CI, -.488 to .096; $p=.188$ )으로 두 집단 간 유의한 차이가 나타나지 않 았다. 


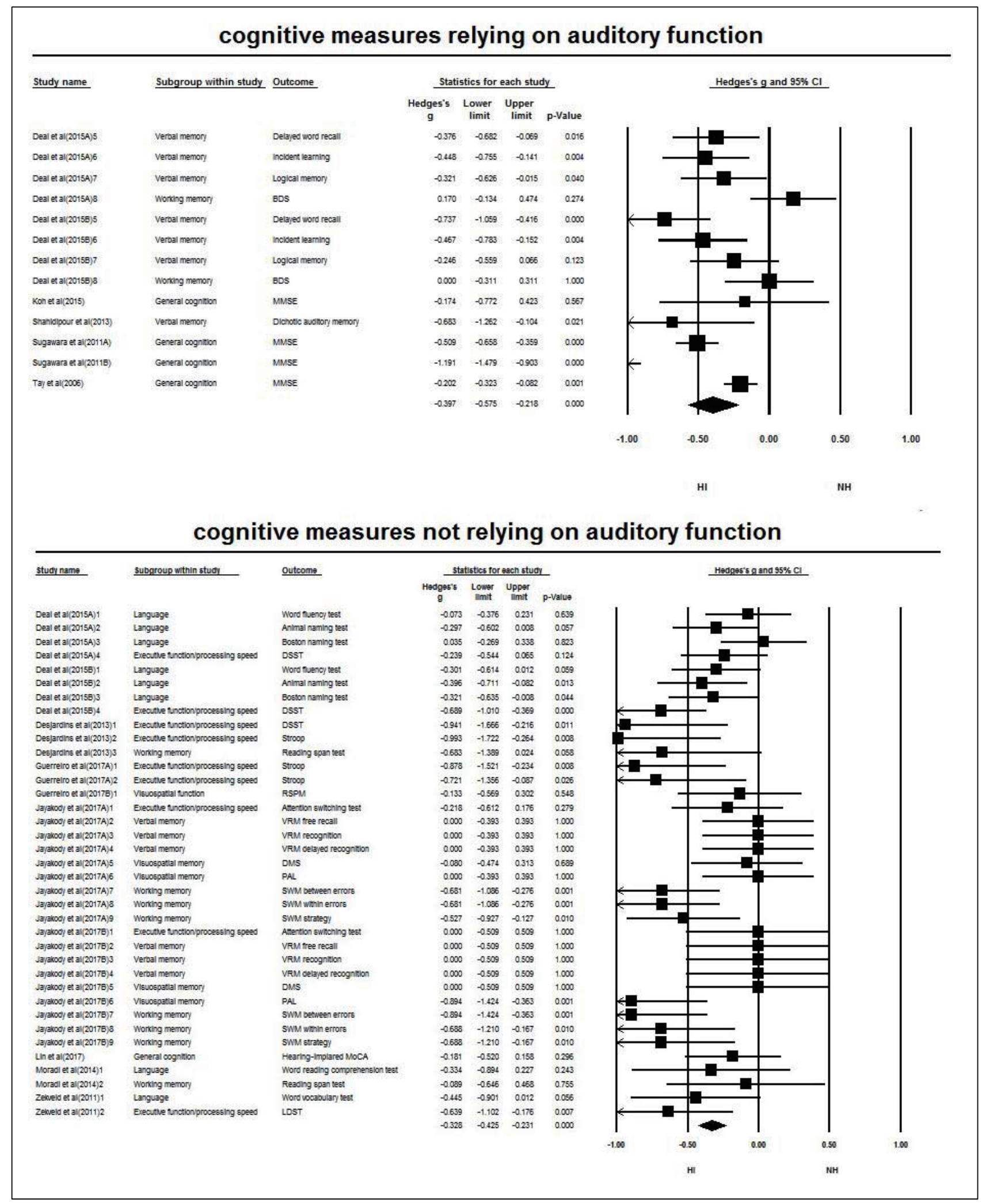

Figure 5. Forest plot for cognitive measures classified into two types.

$\mathrm{HI}=$ hearing-impaired experimental group; $\mathrm{NH}=$ normal-hearing control group. 


\section{청각 기능에 의존하는 정도에 따른 인지과제별 집단 간 수행력 비교}

과제 수행 시에 청각 기능이 주요하게 요구되는가에 따라 인지검 사를 두 부류로 나누어 집단 간 수행력의 차이를 살펴보았다. 청각 기능이 주요하게 요구되는 과제들에서 효과크기 -.397 (95\% CI, -.575 to -.218; $p<.001)$ 이며, 청각 기능이 주요하게 요구되지 않는 과제들에서는 효과크기 -.328 (95\% CI, -.425 to -.231; $p<.001)$ 로서, 두 부류의 과제들에서 모두 청력 손실군이 정상 청력의 대조군에 비해 낮은 수행력을 보였다(Figure 5, Table 3).

\section{논의 및 결론}

본 연구는 메타분석을 통해 장노년층에서 청력 손실군과 정상 청력을 나타내는 대조군 간 인지능력을 비교한 기존 연구결과들을 체계적으로 분석하고자 하였다. 청력 손실군은 정상 청력의 대조 군에 비해 시공간능력을 제외한 대부분의 인지영역, 즉, 전반적 인 지기능, 집행기능 및 정보처리속도, 작업기억, 언어능력, 언어적 기 억력에서 모두 수행력이 저하되었다. 또한, 청각 기능에 대한 의존 도가 높은 인지과제들뿐만 아니라 의존도가 낮은 과제들에서도 청 력 손실군은 대조군에 비해 낮은 수행력을 보였다. 이는 인지검사 에서 청각적 항목을 제외한 이후에도 난청 환자군의 수행력 저하 를 확인하거나(Dupuis et al., 2015), 청각적 인지검사(간이정신상태 검사) 뿐만 아니라 비청각적 인지검사(숫자기호치환검사)에서도 난 청 환자군이 정상 성인에 비해 더 큰 폭으로 수행력이 저하됨을 확 인한 종단연구(Lin et al., 2013)의 결과와도 일맥상통한다.

본 연구결과를 통해서도 확인한 바와 같이, 난청으로 인해 단순 히 검사 자극을 잘 듣지 못해서 인지검사 점수가 저하되는 것이 아 니라면, 난청과 인지저하 간의 관련성을 어떻게 설명할 것인가에 대 해 여러 가지 시도가 이루어져 왔다. 이러한 시도들은 다음의 세 가지 가설로 요약할 수 있는데, 첫째, '정보저하가설(information degradation hypothesis; Schneider \& Pichora-Fuller, 2000)', 둘째, '감각 박탈가설(sensory deprivation hypothesis; Lindenberger \& Baltes, 1994)', 셋째, '공통원인가설(common-cause hypothesis; Baltes \& Lindenberger, 1997)'이다. 첫 번째, 정보저하가설은 난청으로 인해 지각적 노력이 증가됨에 따라 정상 청력의 성인에 비해 제한된 인지 적 용량의 많은 부분을 지각 단계에 사용할 수밖에 없는데, 이로 인 해 다른 인지적 과제를 수행할 나머지 용량이 줄어들고, 따라서 인 지 수행력이 저하된다는 가설이다. 예컨대, 문장을 기억해서 따라 말하는 검사를 시행한다고 가정해보자. 정상 청력의 장노년층은 말소리를 지각하는 데 큰 어려움이 없는 반면, 청력 손실군은 일부
주파수대역의 음향학적 정보가 소실되기 때문에 문맥적/의미적 추 론을 통하여 끊임없이 놓친 정보들을 복구해야 한다. 이처럼 제한 된 인지적 용량의 많은 부분을 말소리 '지각' 단계에서부터 사용하 기 때문에, 문장을 '기억'하기 위해 필요한 인지적 용량은 정상 청력 을 나타내는 장노년층에 비해 줄어들 수밖에 없다. 두 번째, 감각박 탈가설은 앞서 살펴본 정보저하가설의 장기적 영향에 초점을 맞춘 다. 즉, 정보저하가설이 일시적인 인지 수행력 저하를 야기한다면, 감각박탈가설은 이러한 인지 수행력 저하가 장기적으로 지속되면 보다 영구적으로 인지기능 결함을 불러일으킨다는 가설이다. 난청 이 지속되면 대뇌 피질의 변화와 더불어 청각영역의 기능적 재조직이 일어나며(Dietrich, Nieschalk, Stoll, Rajan, \& Pantev, 2001; Meredith, Keniston, \& Allman, 2012; Syka, 2002), 이는 관련 대뇌영역의 지배를 받는 인지기능에도 부정적 영향을 미칠 수 있다(Peelle, Troiani, Grossman, \& Wingfield, 2011). 마지막으로, 공통원인가설은 공통적인 기제에 의해 장노년층의 청각 기능 저하 및 인지기능 감 퇴가 야기된다고 본다. 노화는 광범위한 중추신경계의 퇴행을 일 으키는데, 이로 인해 인지기능이 감퇴할 뿐만 아니라 다영역에 걸 쳐 감각 기능의 저하가 함께 발생할 수 있다. 노화는 청각 기능의 저 하만 야기하는 것이 아니라 시각, 후각 등의 다영역에 걸쳐 감각 기 능을 떨어뜨리며, 이미 다수의 연구들에서 시각과 인지기능(Lindenberger \& Baltes, 1994; Monge \& Madden, 2016), 혹은 후각과 인지기능(Gray, Staples, Murren, Dhariwal, \& Bentham, 2001; Pardini, Huey, Cavanagh, \& Grafman, 2009) 간의 관련성을 보고하였다.

최근에 Wayne과 Johnsrude (2015)는 위의 세 가지 가설들을 통 합함으로써 노인성 난청과 인지저하 간의 관련성을 설명하는 하나 의 새로운 틀을 제시하였다. 즉, 노화로 인한 뇌구조 및 기능의 변화 는 인지감퇴 및 감각 기능의 저하를 야기한다. 감각 기능의 저하로 인해 증가된 지각적 어려움은 인지기능 저하를 촉진하며, 인지기능 저하는 다시 지각적 어려움을 높이며 이 두 가지 요인은 상호 간에 영향을 미친다. 이때, 지각적 어려움이나 인지기능 저하는 우울증 등의 정신적 문제들을 야기하고, 우울증은 다시 인지기능에 악영 향을 미치게 된다. 앞서 살펴본 가설들의 핵심을 이루는 '지각적 어 려움(perceptual difficulty)'이나 '듣기 노력(listening effort)'의 개 념에는 여러 인지영역 가운데서도 특히 작업기억이나 집행기능, 정 보처리속도 등이 중요하게 작용한다. 본 메타분석에 포함된 연구들 의 다수가 작업기억, 집행기능 및 정보처리속도 등을 주로 평가하 였다는 점도 이를 반영한다. 즉, 작업기억 용량이 클수록 지각을 넘 어선 다른 인지적 과제를 수행할 수 있는 용량이 비축된다(Pichora -Fuller, Schneider, \& Daneman, 1995; Rönnberg, Rudner, Lunner, \& Zekveld, 2010). 더불어, 선택적 주의력이나 행동 억제 등을 포함 
하는 개념인 집행기능 역시 주요하게 영향을 미친다. 노인성 난청은 특히 시끄러운 소음 환경에서 말소리를 지각하고 이해하는 데 어려 움을 보이기 때문에, 경쟁자극의 간섭효과를 억제하고 목표 말소리 에만주의를 기울일 수 있는 능력은 매우 중요하다(Gates et al., 2010; Lee, Park, Kim, \& Kim, 2016). 또한, 대화 상황에서 지속적으로 말 소리를 지각하고 메시지를 이해하기 위해서는 문맥적/의미적 단서 들을 활용하여 놓친 정보를 최대한 빠르게 복구할 수 있어야 한다 (Rönnberg et al., 2010). 본 연구에서 확인한 바와 같이, 청력 손실 을 나타내는 장노년층은 정상 청력의 대조군에 비해 집행기능 및 정보처리속도, 작업기억이 모두 저하되며, 이는 언어능력이나 언어 적 기억력 보다도 더 큰 효과크기를 나타내었다. 즉, Wayne과 Johnsrude (2015)가 제시하였듯이, 난청으로 인한 지각적 어려움은 인 지능력의 저하를 야기하며, 이러한 인지능력의 저하, 특히 작업기억 이나 집행기능의 저하는 다시 지각적 어려움을 높임으로써 양방향 으로 상호간 부정적 영향을 미치게 된다.

본 연구에서 한 가지 주목할만한 점은 청력 손실군과 정상 청력 의 대조군 간에 시공간 능력에는 차이가 나타나지 않았다는 사실 이다. 시공간 능력을 측정하는 인지검사들로는, 복잡한 시각적 패 턴을 재인하여 즉각적으로, 혹은 일정 시간이 지난 후에 제시된 보기 들 가운데 동일한 패턴을 고르는 지연표본대응과제(delayed matching to sample task), 컴퓨터 화면 제각각의 위치에서 제시되는 다양 한 색깔과 모양의 도형들을 기억한 후에 뒤이어 제시되는 도형이 앞 서 본 도형들 중에 무엇이었는지 기억하여 고르는 쌍연합학습검사 (paired associates learning test), 기하학적 패턴의 도형 가운데 빈 칸에 들어갈 적절한 패턴을 제시된 보기들 가운데 유추하여 고르 는 레이븐 매트릭스 검사(Raven's Standard Progressive Matrices) 등이 포함되었다. 본 연구결과는 청력이 저하된 장노년층에서도 비 언어적인 시공간적 정보를 처리하거나 기억하는 능력은 정상 청력 의 대조군과 비슷하게 유지됨을 나타낸다. 이는 난청 환자들이 청 력 손실로 인해 제한될 수밖에 없는 청각적 정보를 보상하기 위하 여 시각적인 정보에 더욱 의존하는 경향이 반영된 결과일 수 있겠 으나, 본 메타분석에는 시공간구성 능력을 측정하는 일부 검사들 이 제한적으로 포함되었으므로 이러한 논의를 보다 일반화하기 위 해서는 추후 더욱 다양한 연구들을 종합하여 분석할 필요가 있을 것이다.

본 메타분석 연구는 기존의 개별 연구들이 도출한 비일관적인 결과를 통합함으로써 난청이 있는 장노년층이 청력이 정상 범위에 있는 장노년층에 비해 인지능력이 저하된다는 사실을 확인하고, 나아가 난청과 인지기능 저하 간의 관련성을 기존의 가설에 비추어 설명하였다. 본 연구는 장노년층을 대상으로 난청과 인지기능 간의
관련성을 분석한 첫 번째 메타분석이라는 점에서 의의가 있으나, 대상자의 난청 중증도 및 보청기 착용 여부를 통제하지 못했다는 측면에서 제한점이 있다. 본 메타분석에는 다양한 중증도의 난청 이 포함되었으며, 일부 연구들은 보청기 착용자를 포함한 반면 일 부에서는 포함하지 않았고, 대상자의 보청기 착용 여부에 대한 정 보가 제시되지 않은 경우가 가장 많았다. 최근 들어 사전사후검사 를 통해 보청기 사용이 인지기능에 미치는 영향을 밝히고자 하는 연구들이 잇따라 시행되고 있으므로(Van Hooren et al., 2005), 향 후 노인성 난청과 인지기능 간 관련성에 주목한 더욱 많은 수의 연 구들이 시행된다면, 대상자의 청력 손실 정도 및 보청기 사용의 영 향을 통제한 메타분석이 이루어질 필요가 있겠다. 더불어, 본 메타 분석은 횡단적 연구들로만 한정하여 시행하였는데, 이처럼 특정 한 시점의 집단 비교를 통해서는 시간에 따른 개인 내 인지기능의 변화를 탐지하지 못한다는 문제가 있다. 궁극적으로 노인성 난청이 장노년층의 인지기능 감퇴를 가속화하고 치매 등의 인지장애를 유 발하는 위험인자임을 밝히기 위해서는 종단적 연구들을 체계적으 로 분석할 필요가 있다. 추후 종단연구들을 대상으로 한 메타분석 을 통해 난청이 인지기능에 미치는 장기적 효과를 파악할 수 있을 것으로 기대한다.

\section{REFERENCES}

Agrawal, Y., Platz, E. A., \& Niparko, J. K. (2008). Prevalence of hearing loss and differences by demographic characteristics among US adults: data from the National Health and Nutrition Examination Survey, 1999-2004. Archives of Internal Medicine, 168, 1522-1530.

Albers, M. W., Gilmore, G. C., Kaye, J., Murphy, C., Wingfield, A., Bennett, D. A., ... \& Duffy, C. J. (2015). At the interface of sensory and motor dysfunctions and Alzheimer's disease. Alzheimer's \& Dementia, 11, 70-98.

Anstey, K. J., Luszcz, M. A., \& Sanchez, L. (2001). Two-year decline in vision but not hearing is associated with memory decline in very old adults in a population-based sample. Gerontology, 47, 289-293.

Baltes, P. B., \& Lindenberger, U. (1997). Emergence of a powerful connection between sensory and cognitive functions across the adult life span: a new window to the study of cognitive aging? Psychology and Aging, 12, 12-21.

Bopp, K. L., \& Verhaeghen, P. (2005). Aging and verbal memory span: a meta-analysis. The Journals of Gerontology Series B: Psychological Sciences and Social Sciences, 60, P223-P233.

Buckner, R. L. (2004). Memory and executive function in aging and AD: multiple factors that cause decline and reserve factors that compensate. 
Neuron, 44, 195-208.

Ciorba, A., Bianchini, C., Pelucchi, S., \& Pastore, A. (2012). The impact of hearing loss on the quality of life of elderly adults. Clinical Interventions in Aging, 7, 159-163.

Connor, L. T. (2001). Memory in old age: patterns of decline and preservation. Seminars in Speech and Language, 22, 117-125.

Deal, J. A., Sharrett, A. R., Albert, M. S., Coresh, J., Mosley, T. H., Knopman, D., ... \& Lin, F. R. (2015). Hearing impairment and cognitive decline: a pilot study conducted within the atherosclerosis risk in communities neurocognitive study. American Journal of Epidemiology, 181, 680-690.

Desjardins, J. L., \& Doherty, K. A. (2013). Age-related changes in listening effort for various types of masker noises. Ear and Hearing, 34, 261-272.

Dietrich, V., Nieschalk, M., Stoll, W., Rajan, R., \& Pantev, C. (2001). Cortical reorganization in patients with high frequency cochlear hearing loss. Hearing Research, 158, 95-101.

Dupuis, K., Pichora-Fuller, M. K., Chasteen, A. L., Marchuk, V., Singh, G., \& Smith, S. L. (2015). Effects of hearing and vision impairments on the Montreal Cognitive Assessment. Aging, Neuropsychology, and Cognition, 22, 413437.

Egger, M., Smith, G. D., Schneider, M., \& Minder, C. (1997). Bias in metaanalysis detected by a simple, graphical test. BMJ, 315, 629-634.

Gates, G. A., \& Mills, J. H. (2005). Presbycusis. The Lancet, 366, 1111-1120.

Gates, G. A., Gibbons, L. E., McCurry, S. M., Crane, P. K., Feeney, M. P., \& Larson, E. B. (2010). Executive dysfunction and presbycusis in older persons with and without memory loss and dementia. Cognitive and Behavioral Neurology, 23, 218-223.

Gersten, R., Fuchs, L. S., Compton, D., Coyne, M., Greenwood, C., \& Innocenti, M. S. (2005). Quality indicators for group experimental and quasiexperimental research in special education. Exceptional Children, 71, 149164.

Gray, A. J., Staples, V., Murren, K., Dhariwal, A., \& Bentham, P. (2001). Olfactory identification is impaired in clinic-based patients with vascular dementia and senile dementia of Alzheimer type. International Journal of Geriatric Psychiatry, 16, 513-517.

Guerreiro, M. J., \& Van Gerven, P. W. (2017). Disregarding hearing loss leads to overestimation of age-related cognitive decline. Neurobiology of Aging, 56, $180-189$.

Homans, N. C., Metselaar, R. M., Dingemanse, J. G., van der Schroeff, M. P., Brocaar, M. P., Wieringa, M. H., ... \& Goedegebure, A. (2017). Prevalence of age-related hearing loss, including sex differences, in older adults in a large cohort study. The Laryngoscope, 127, 725-730.

Hwang, S. D. (2014). Meta-analysis. Seoul: Hakjisa.

Hwang, Y. K., \& Kim, H. (2014). Utility of the Boston Naming test in differentiating between mild cognitive impairment and normal elderly: a metaanalysis. Communication Sciences \& Disorders, 19, 501-512.

Jayakody, D. M., Friedland, P. L., Eikelboom, R. H., Martins, R. N., \& Sohrabi, H. R. (2018). A novel study on association between untreated hearing loss and cognitive functions of older adults: baseline non-verbal cognitive assessment results. Clinical Otolaryngology, 43, 182-191.

Katsarkas, A., \& Ayukawa, H. (1986). Hearing loss due to aging (presbycusis). The Journal of Otolaryngology, 15, 239-244.

Koh, D. H., Lee, J. D., \& Lee, H. J. (2015). Relationships among hearing loss, cognition and balance ability in community-dwelling older adults. Journal of Physical Therapy Science, 27, 1539-1542.

Lee, S. J., Park, K. W., Kim, L. S., \& Kim, H. (2016). Effects of noise level and cognitive function on speech perception in normal elderly and elderly with amnestic mild cognitive impairment. Cognitive and Behavioral Neurology, $29,68-77$

Lethbridge-Cejku, M., Schiller, J. S., \& Bernadel, L. (2004). Summary health statistics for US adults: National Health Interview Survey, 2002. Vital and Health Statistics Series 10, (222), 1-151.

Lin, F. R., Ferrucci, L., Metter, E. J., An, Y., Zonderman, A. B., \& Resnick, S. M. (2011b). Hearing loss and cognition in the Baltimore Longitudinal Study of Aging. Neuropsychology, 25, 763-770.

Lin, F. R., Metter, E. J., O’Brien, R. J., Resnick, S. M., Zonderman, A. B., \& Ferrucci, L. (2011a). Hearing loss and incident dementia. Archives of Neurology, 68, 214-220.

Lin, F. R., Yaffe, K., Xia, J., Xue, Q. L., Harris, T. B., Purchase-Helzner, E., ... \& Health ABC Study Group, F. (2013). Hearing loss and cognitive decline in older adults. JAMA Internal Medicine, 173, 293-299.

Lin, M. Y., Gutierrez, P. R., Stone, K. L., Yaffe, K., Ensrud, K. E., Fink, H. A., ... \& Mangione, C. M. (2004). Vision impairment and combined vision and hearing impairment predict cognitive and functional decline in older women. Journal of the American Geriatrics Society, 52, 1996-2002.

Lin, V. Y., Chung, J., Callahan, B. L., Smith, L., Gritters, N., Chen, J. M., ... \& Masellis, M. (2017). Development of cognitive screening test for the severely hearing impaired: hearing-impaired MoCA. The Laryngoscope, 127(S1), S1-S11.

Lindenberger, U., \& Baltes, P. B. (1994). Sensory functioning and intelligence in old age: a strong connection. Psychology and Aging, 9, 339-355. 
Lindenberger, U., Scherer, H., \& Baltes, P. B. (2001). The strong connection between sensory and cognitive performance in old age: not due to sensory acuity reductions operating during cognitive assessment. Psychology and Aging, 16, 196-205.

McCabe, D. P., Roediger, H. L., McDaniel, M. A., Balota, D. A., \& Hambrick, D. Z. (2010). The relationship between working memory capacity and executive functioning: evidence for a common executive attention construct. Neuropsychology, 24, 222-243.

Meredith, M. A., Keniston, L. P., \& Allman, B. L. (2012). Multisensory dysfunction accompanies crossmodal plasticity following adult hearing impairment. Neuroscience, 214, 136-148.

Monge, Z. A., \& Madden, D. J. (2016). Linking cognitive and visual perceptual decline in healthy aging: the information degradation hypothesis. Neuroscience \& Biobehavioral Reviews, 69, 166-173.

Moradi, S., Lidestam, B., Hällgren, M., \& Rönnberg, J. (2014). Gated auditory speech perception in elderly hearing aid users and elderly normal-hearing individuals: effects of hearing impairment and cognitive capacity. Trends in Hearing, 18, 1-12.

Panza, F., Solfrizzi, V., \& Logroscino, G. (2015). Age-related hearing impairment: a risk factor and frailty marker for dementia and $\mathrm{AD}$. Nature Reviews Neurology, 11, 166-175.

Pardini, M., Huey, E. D., Cavanagh, A. L., \& Grafman, J. (2009). Olfactory function in corticobasal syndrome and frontotemporal dementia. Archives of Neurology, 66, 92-96.

Peelle, J. E., Troiani, V., Grossman, M., \& Wingfield, A. (2011). Hearing loss in older adults affects neural systems supporting speech comprehension. Journal of Neuroscience, 31, 12638-12643.

Pichora-Fuller, M. K., Schneider, B. A., \& Daneman, M. (1995). How young and old adults listen to and remember speech in noise. The Journal of the Acoustical Society of America, 97, 593-608.

Rönnberg, J., Rudner, M., Lunner, T., \& Zekveld, A. A. (2010). When cognition kicks in: Working memory and speech understanding in noise. Noise and Health, 12, 263-269.

Rönnlund, M., Nyberg, L., Bäckman, L., \& Nilsson, L. G. (2005). Stability, growth, and decline in adult life span development of declarative memory: cross-sectional and longitudinal data from a population-based study. Psy- chology and Aging, 20, 3-18.

Salthouse, T. A. (1996). The processing-speed theory of adult age differences in cognition. Psychological Review, 103, 403-428.

Salthouse, T. A. (2009). When does age-related cognitive decline begin? Neurobiology of Aging, 30, 507-514.

Schneider, B. A., \& Pichora-Fuller, M. K. (2000). Implications of perceptual deterioration for cognitive aging research. In F. I. M. Craik \& T. A. Salthouse (Eds.), The handbook of aging and cognition (pp. 155-219). Mahwah, NJ: Lawrence Erlbaum Associates.

Shahidipour, Z., Geshani, A., Jafari, Z., Jalaie, S., \& Khosravifard, E. (2013). Auditory memory deficit in elderly people with hearing loss. Iranian Journal of Otorhinolaryngology, 25, 169-176.

Sugawara, N., Sasaki, A., Yasui-Furukori, N., Kakehata, S., Umeda, T., Namba, A., ... \& Kaneko, S. (2011). Hearing impairment and cognitive function among a community-dwelling population in Japan. Annals of General Psychiatry, 10, 27-33.

Syka, J. (2002). Plastic changes in the central auditory system after hearing loss, restoration of function, and during learning. Physiological Reviews, $82,601-636$.

Taljaard, D. S., Olaithe, M., Brennan-Jones, C. G., Eikelboom, R. H., \& Bucks, R. S. (2016). The relationship between hearing impairment and cognitive function: a meta-analysis in adults. Clinical Otolaryngology, 41, 718-729.

Tay, T., Wang, J. J., Kifley, A., Lindley, R., Newall, P., \& Mitchell, P. (2006). Sensory and cognitive association in older persons: findings from an older Australian population. Gerontology, 52, 386-394.

van Hooren, S. A., Anteunis, L. J., Valentijn, S. A., Bosma, H., Ponds, R. W. H. M., Jolles, J., \& van Boxtel, M. P. J. (2005). Does cognitive function in older adults with hearing impairment improve by hearing aid use? International Journal of Audiology, 44, 265-271.

Wayne, R. V., \& Johnsrude, I. S. (2015). A review of causal mechanisms underlying the link between age-related hearing loss and cognitive decline. Ageing Research Reviews, 23, 154-166.

Zekveld, A. A., Kramer, S. E., \& Festen, J. M. (2011). Cognitive load during speech perception in noise: the influence of age, hearing loss, and cognition on the pupil response. Ear and Hearing, 32, 498-510. 


\section{국문초록}

\section{장노년층에서 난청과 인지기능 간의 관련성에 대한 메타분석 \\ 이수정}

대구가톨릭대학교 언어청각치료학과

배경 및 목적: 난청이 인지기능에 미치는 영향을 파악하기 위한 다수의 연구들이 이루어지고 있으나, 그 결과는 비교적 일관적이지 않 다. 이에, 본 연구는 메타분석을 통하여 장노년층에서 청력 손실군과 정상 청력을 나타내는 대조군 간 인지능력을 비교한 문헌들을 체 계적으로 분석함으로써 장노년층의 난청과 인지기능 간 관련성에 대한 종합적인 결과를 도출하고자 하였다. 방법: 국내외 관련 문헌들 을 검토한 후 연구 포함 및 제외기준에 따라 총 11편의 연구를 선정하였다. 무선효과모델(random effect model)을 사용하여 효과크기 를 산출하였고, 분석방법은, 첫째, 종합적 인지능력을 분석, 둘째, 인지영역(전반적 인지기능, 집행기능/정보처리속도, 작업기억, 언어, 언 어적 기억, 시공간 능력)에 따라 분석, 셋째, 인지과제(청각 기능에 대한 의존도가 높은 과제 및 낮은 과제)에 따라 분석하였다. 결과: 청 력 손실군은 정상 청력의 대조군에 비해 인지능력이 저하되는데, 특히, 전반적 인지기능, 집행기능/정보처리속도, 작업기억, 언어, 언어 적 기억력에서 저하된 수행력을 보였으며, 시공간 능력에서는 두 집단 간 차이가 나타나지 않았다. 또한, 청력 손실군은 청각 기능에 대 한 의존도가 높은 인지과제들뿐만 아니라 낮은 과제들에서도 대조군에 비해 수행력이 저하되었다. 논의 및 결론: 본 연구결과는 장노 년층에서의 난청이 인지기능 저하와 관련성이 있음을 시사한다.

핵심어: 난청, 인지기능, 장노년층, 메타분석

\section{참고문헌}

황성동(2014). 알기 쉬운 메타분석의 이해. 서울: 학지사.

황윤경, 김향희(2014). 경도인지장애 변별을 위한 보스턴 이름대기 검사의 유용성: 메타분석. 언어청각장애연구, 19, 501-512. 